\title{
Modulation of lung inflammation by vessel dilator in a mouse model of allergic asthma
}

Xiaoqin Wang ${ }^{1,2}$, Weidong $\mathrm{Xu}^{2}$, Xiaoyuan Kong2 ${ }^{2}$ Dongqing Chen ${ }^{2}$, Gary Hellermann ${ }^{2}$, Terry A Ahlert ${ }^{4}$, Joseph D Giaimo ${ }^{4}$, Stephania A Cormier ${ }^{4}$, $\mathrm{Xu} \mathrm{Li}^{1}$, Richard F Lockey ${ }^{2,5}$, Subhra Mohapatra ${ }^{3,5}$ and Shyam S Mohapatra*2,5

Address: ${ }^{1}$ Clinical Laboratory Center of First Affiliated Hospital, Xi'an Jiaotong University College of Medicine, Xi'an, PR China, ${ }^{2}$ Division of Allergy and Immunology, University of South Florida, Tampa, FL 33612, USA, ${ }^{3}$ Division of Endocrinology, Department of Internal Medicine, University of South Florida, Tampa, FL 33612, USA, ${ }^{4}$ Department of Pharmacology and Experimental Therapeutics, Louisiana State University Health Sciences Center, New Orleans, LA 70112, USA and ${ }^{5}$ VA Hospital Medical Center, Tampa, FL 33612, USA

Email: Xiaoqin Wang - xwang1@health.usf.edu; WeidongXu - wxu@health.usf.edu; Xiaoyuan Kong - xkong@health.usf.edu; Dongqing Chen - dchen@health.usf.edu; Gary Hellermann - ghellerm@ health.usf.edu; Terry A Ahlert - tahler@lsuhsc.edu; Joseph D Giaimo - jgiaim@lsuhsc.edu; Stephania A Cormier - scorm1@lsuhsc.edu; Xu Li - lixu@tom.com;

Richard F Lockey - rlockey@ health.usf.edu; Subhra Mohapatra - smohapa2@health.usf.edu; Shyam S Mohapatra* - smohapat@health.usf.edu

* Corresponding author

Published: 17 July 2009

Respiratory Research 2009, 10:66 doi:10.1186/1465-9921-10-66

This article is available from: http://respiratory-research.com/content//0/I/66

(C) 2009 Wang et al; licensee BioMed Central Ltd.

This is an Open Access article distributed under the terms of the Creative Commons Attribution License (http://creativecommons.org/licenses/by/2.0), which permits unrestricted use, distribution, and reproduction in any medium, provided the original work is properly cited.
Received: 3 October 2008

Accepted: 17 July 2009

\begin{abstract}
Background: Atrial natriuretic peptide (ANP) and its receptor, NPRA, have been extensively studied in terms of cardiovascular effects. We have found that the ANP-NPRA signaling pathway is also involved in airway allergic inflammation and asthma. ANP, a C-terminal peptide (amino acid 99-126) of pro-atrial natriuretic factor (proANF) and a recombinant peptide, NP73-I02 (amino acid 73-102 of proANF) have been reported to induce bronchoprotective effects in a mouse model of allergic asthma. In this report, we evaluated the effects of vessel dilator (VD), another $\mathrm{N}$-terminal natriuretic peptide covering amino acids $31-67$ of proANF, on acute lung inflammation in a mouse model of allergic asthma.
\end{abstract}

Methods: A549 cells were transfected with PVD or the PVAXI control plasmid and cells were collected $24 \mathrm{hrs}$ after transfection to analyze the effect of VD on inactivation of the extracellularsignal regulated receptor kinase (ERKI/2) through western blot. Luciferase assay, western blot and RT-PCR were also performed to analyze the effect of VD on NPRA expression. For determination of VD's attenuation of lung inflammation, BALB/c mice were sensitized and challenged with ovalbumin and then treated intranasally with chitosan nanoparticles containing PVD. Parameters of airway inflammation, such as airway hyperreactivity, proinflammatory cytokine levels, eosinophil recruitment and lung histopathology were compared with control mice receiving nanoparticles containing PVAXI control plasmid.

Results: PVD nanoparticles inactivated ERKI/2 and downregulated NPRA expression in vitro, and intranasal treatment with PVD nanoparticles protected mice from airway inflammation.

Conclusion: VD's modulation of airway inflammation may result from its inactivation of ERK I/2 and downregulation of NPRA expression. Chitosan nanoparticles containing PVD may be therapeutically effective in preventing allergic airway inflammation. 


\section{Background}

Asthma is a complex disease, characterized by reversible airway obstruction, airway hyperresponsiveness and chronic airway inflammation. According to the Third National Health Nutrition Examination Survey, about $54 \%$ of the US population is allergic to one or more allergens, and over the last two decades, the rates of asthma have increased worldwide [1]. Current pharmacologic treatments for asthma include bronchodilating beta2-agonists and antiinflammatory glucocorticosteroids. These agents act only on symptoms and do not target the main cause of the disease, the generation of pathogenic Th2 cells [2-5]. Hence, there is a continued search for novel agents against allergy and asthma.

The family of natriuretic hormone peptides has broad physiologic effects including vasodilation, cardiovascular homeostasis, sodium excretion and inhibition of aldosterone secretion. There have been several reports demonstrating involvement of the atrial natriuretic peptide (ANP) signaling pathway in immunity in the heart and lung [6]. The natriuretic peptide prohormone is a polypeptide of 126 amino acids that gives rise to four peptides: long acting natriuretic peptide (LANP, amino acids 1-30), vessel dilator (VD, amino acids 31-67), kaliuretic peptide (KP, amino acids 79-98) and atrial natriuretic peptide (ANP, amino acids 99-126) [7]. In contrast to ANP, the N-terminal proANP peptides (LANP, VD, KP) are slowly metabolized and their plasma concentration is higher than ANP consistent with their important role in electrolyte balance and regulation of vascular tone. ANP and its principal receptor, NPRA, have been extensively studied in terms of cardiovascular effects [8]. ANP signals primarily through NPRA by increasing cGMP and activating cGMP-dependent protein kinase (PKG). Activated PKG turns on ion transporters and transcription factors, which together affect cell growth and proliferation, and inflammation [6]. NPRA is widely expressed in the lung and has been associated with allergic inflammation and asthma [9-11].

We have reported that both ANP and NP73-102 showed bronchoprotective effects $[12,13]$. Expression of NP73102 induced constitutive nitric oxide production and decreased activation of a number of transcription factors including nuclear factor kappa B in human epithelial cells [13]. However, there is no report of the functions of the $\mathrm{N}$ terminal proANP peptides including LANP, VD and KP in modulating lung inflammation. In this report we show that overexpression of VD attenuates airway inflammation in a mouse model of allergic asthma. The effects of VD on airway inflammation may result from its inactivation of ERK1/2 and downregulation of NPRA expression.

\section{Methods \\ Mice}

BALB/c mice were purchased from Harlan Sprague Dawley, Inc. and maintained under specific pathogen-free conditions within the vivarium at Louisiana State University Health Sciences Center (New Orleans, LA) or at the University of South Florida (Tampa, FL). Sentinel mice within each colony were monitored and were negative for specific known mouse pathogens. All animal protocols were prepared in accordance with the Guide for the Care and Use of Laboratory Animals (National Research Council, 1996) and approved by the Institutional Animal Care and Use Committee at Louisiana State University Health Sciences Center or at University of South Florida.

\section{Preparation of pVD chitosan nanoparticles}

The cDNAs encoding VD were cloned between the EcoRI and XhoI sites of the mammalian expression vector PVAX1 (Invitrogene, CA) using standard molecular biology procedures. Similarly, we also constructed a plasmid, pMut, which expresses a mutated VD peptide with the reversed amino acid sequence of VD. Stocks of pVD, pMut and pVAX1 plasmids were prepared using Qiagene endotoxinfree Gigaprep kits (Qiagen, CA). We have developed a nanoparticle delivery system utilizing the polysaccharide chitosan that allows intranasal administration of peptides, plasmids, and drugs [14]. The nanoparticles protect the natriuretic peptide expression plasmids from nuclease degradation and improve delivery to cells. Complex coacervation of the DNA with chitosan (33 $k \mathrm{Da} a$, with $90 \%$ deacetylation, obtained from TaeHoon Bio (Korea) at a chitosan:DNA weight ratio of 1:3) was achieved by vortexing for $2 \mathrm{~min}$ at room temperature. Coacervates were used immediately after preparation or stored at $4{ }^{\circ} \mathrm{C}$.

\section{Analysis of ERKI/2 expression and NPRA in PVD- transfected cells by Western blot}

A549 human alveolar carcinoma epithelial cells (ATCC, Manassas, VA) were grown in 6-well plates and transfected with $1 \mu \mathrm{g}$ of pVD or pVAX1 using Fugene 6 under manufacture's instruction (Roche, NJ). To extract whole-cell protein, cells were harvested $48 \mathrm{hrs}$ after transfection and resuspended in lysis buffer containing $50 \mathrm{mM}$ HEPES, 150 $\mathrm{mM} \mathrm{NaCl}, 1 \mathrm{mM}$ EDTA, 1 mM EGTA, 10\% glycerol, 0.5\% NP-40, $0.1 \mathrm{mM}$ phenylmethylsulfonyl fluoride, $2.5 \mu \mathrm{g} / \mathrm{ml}$ leupeptin, $0.5 \mathrm{mM} \mathrm{NaF}$, and $0.1 \mathrm{mM}$ sodium vanadate. Fifty $\mu \mathrm{g}$ of protein was subjected to sodium dodecyl sulfate-polyacrylamide gel electrophoresis on a $10 \%$ polyacrylamide gel and then transferred onto nitrocellulose membranes. Western blotting was performed using primary antibodies against extracellular signal-regulated kinase (ERK) $1 / 2$ according to the manufacturer's instructions (Cell Signaling Technology, Beverly, MA). For analysis of the effect of VD on NPRA expression in vitro, HEKGCA (human embryonic kidney cells stably transfected 
with the natriuretic peptide receptor, GC-A, which is the same as NPRA) cells grown in 6-well plates were transfected with $1 \mu \mathrm{g}$ of pVAX1, pVD or pMut. Differential expression of NPRA was detected by western blot using primary antibody against NPRA (Santa Cruz Biotechnology, CA).

\section{Luciferase assay to analyze the VD effect on NPRA promoter activity}

Human embryonic kidney cells (HEK293; ATCC, Manassas, VA) were grown on 6-well plates and co-transfected with $1 \mu \mathrm{g}$ of pVD plus $0.5 \mu \mathrm{g}$ of pNPRA-Luc(-1575) which contains the 1575-bp fragment of NPRA promoter inserted upstream of the luciferase gene. In the control wells, cells were co-transfected with $1 \mu \mathrm{g}$ of empty vector, pVAX1, and $0.5 \mu \mathrm{g}$ pNPRA-Luc (-1575). Forty-eight hrs later, cells were washed with PBS, scraped off and suspended in $200 \mu$ l of luciferase assay lysis buffer (Promega, Madison, WI). Cell suspensions were kept on ice for 15 min and then vortexed for $15 \mathrm{sec}$ before centrifugation for $1 \mathrm{~min}$ at 13,200 rpm. The supernatant was removed and aliquots were stored at $-80^{\circ} \mathrm{C}$. After protein concentration measurement, equal amounts of total protein from each transfection assayed for luciferase according to manufacturer's instructions (Pierce Biotechnology Inc., Rockford, IL).

\section{RT-PCR detection of NPRA expression in the lung}

For analysis of the effect of VD on NPRA expression in vivo, three groups of mice $(\mathrm{n}=4)$ were intranasally treated with $50 \mu \mathrm{l}$ of chitosan nanoparticles containing $20 \mu \mathrm{g}$ of pVAX1, pVD or pMut. Mice were sacrificed 48 hrs after nanoparticle treatment and lungs were collected. Approximately $100 \mathrm{mg}$ of lung tissue from each mouse was treated with RNAlater (Invitrogen, CA), and total cellular RNA was extracted using Trizol reagent (Invitrogen, CA). RNA from each mouse was reverse transcribed and analyzed for NPRA by RT-PCR by using the following primers: NPRA-forward: 5'-cctgagtacttggaattcctgaagc-3'; NPRAreverse, 5 '-gttccacatccgctgagtgatgtt-3'. Mouse $\beta$-actin was used as housekeeping gene.

\section{Sensitization and induction of allergic airway response with OVA}

Mice (4-5 weeks old) were sensitized and challenged with chicken ovalbumin grade V (OVA; Sigma, St. Louis, MO) as previously described [15]. Briefly, mice were sensitized by an intraperitoneal injection $(100 \mu \mathrm{l})$ of $20 \mu \mathrm{g}$ OVA emulsified in $2 \mathrm{mg}$ Imject Alum (Al $[\mathrm{OH}] 3 / \mathrm{Mg}[\mathrm{OH}] 2$; Pierce, Rockford, IL) on days 0 and 14 (Fig. 1). Mice were subsequently challenged with an OVA aerosol generated using an ultrasonic nebulizer (PariNeb Pro Nebulizer) from a 1\% (wt/vol) OVA solution in saline for $20 \mathrm{~min}$ on days 24, 25, and 26. Nanoparticles (NPs) containing plasmids were administered intranasally (i.n.) on days 25, 26, and 27. Aerosolized OVA challenges were done six hours prior to i.n. NP treatment on days 25 and 26. The four groups of animals were: (1) naïve/pVAX1 $(n=8)$, exposed to vehicle and treated i.n. with $20 \mu \mathrm{g}$ of NPs containing the pVAX1 control vector in $50 \mu \mathrm{l}$ saline; (2) OVA/pVD20 $(n=6)$, sensitized and challenged with OVA and treated i.n. with $20 \mu \mathrm{g}$ of NPs in $50 \mu \mathrm{l}$ saline containing the pVD treatment vector; (3) OVA/pVAX1 $(n=8)$, sensitized and challenged with OVA and treated with empty vector; and (4) OVA only $(n=8)$, sensitized and challenged with OVA with no treatment. Pulmonary function testing was performed on day 28 (mice were 9 wks of age).

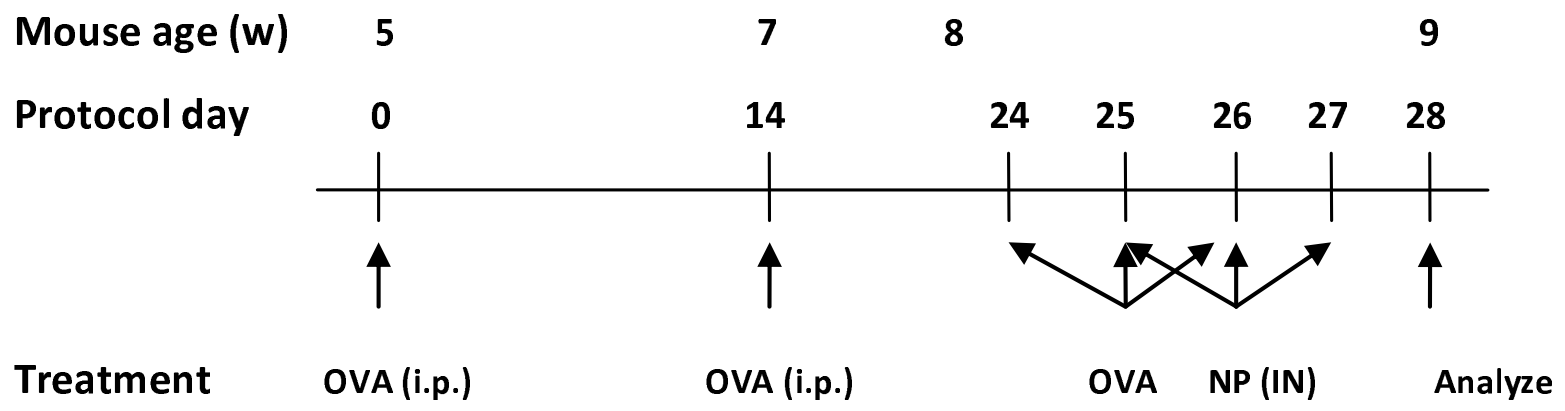

Figure I

Experimental schedule of sensitization and induction of allergic airway response. Chicken ovalbumin was used to sensitize and challenge mice ( $n=6-8$ per group). 


\section{Measurement of airway responsiveness to methacholine} Pulmonary resistance was measured using the forced oscillation technique as previously described [15]. Two sets of experiments that each included mice from all four experimental groups were performed on different days. Anesthetized animals were mechanically ventilated with a tidal volume of $10 \mathrm{ml} / \mathrm{kg}$ and a frequency of $2.5 \mathrm{~Hz}$ using a computer-controlled piston ventilator (Flexivent, SCIREQ; Montreal, Canada). Responses were determined in response to increasing concentrations of aerosolized methacholine (MeCh, at 0, 6.25, 12.5, and $25 \mathrm{mg} / \mathrm{ml}$ in isotonic saline). The single compartment model was used to determine airway resistance values and peak values obtained after each MeCh challenge were plotted [16].

\section{Modulation of lung inflammation by VD}

To test the effects of VD on airway inflammation, a separate experiment was performed. BALB/c mice were divided into four groups ( $n=8$ per group). One group served as naïve control with no OVA sensitization and challenge while the second group received OVA sensitization and OVA challenge on days 18, 19, 20 and 21. Animals in the third group got OVA sensitization, OVA challenge and i.n. treatment with VD NPs on day 18, 19, 20 and 21. The last group was OVA sensitized and challenged, but treated with control NPs containing pVAX1. All mice were sacrificed on day 23 to collect bronchoalveolar lavage (BAL) fluid. Lungs were rinsed with intratracheal injections of PBS, perfused with 10\% neutral buffered formalin, then removed, paraffin-embedded, sectioned at $20 \mu \mathrm{m}$ and stained with hematoxylin and eosin ( $\mathrm{H} \& \mathrm{E})$. Lung homogenates for cytokine measurement were also prepared.

For differential cell enumeration, BAL fluid was centrifuged at 1,200 rpm for $5 \mathrm{~min}$ and the cell pellet was suspended in $200 \mu \mathrm{l}$ of PBS and counted using a hemocytometer. The cell suspensions were centrifuged onto glass slides using a cytospin centrifuge at 1,000 rpm for $5 \mathrm{~min}$ at room temperature. Cytocentrifuged cells were air dried and stained with a modified Wright's stain (Leukostat, Fisher Scientific, Atlanta, GA) which allows differential counting of monocytes and lymphocytes. At least 300 cells per sample were counted by direct microscopic observation. For evaluation of proinflammatory cytokines, the levels of IL-2, IL-4, IL-5, IL-13, IFN- $\gamma$ and TNF $\alpha$ in lung homogenates were measured using a mouse Th1/Th2 Cytokine CBA kit following the manufacturer's instruction (BD Bioscience, CA).

\section{Statistical analysis}

All experiments were repeated at least once. The data are expressed as means \pm SEM (standard error of the mean) and differences are considered significant at $p<0.05$.
Comparisons were done using the 2-tailed Student's $t$ test or 2-way ANOVA with Bonferroni post-test.

\section{Results}

\section{VD prevented ERKI/2 activation in $A 549$ cells}

Increased synthesis of nitric oxide (NO) during airway inflammation caused by induction of nitric oxide synthase- 2 in several lung cell types may contribute to epithelial injury and permeability. Analysis of signaling pathways indicated ERK1/2 dephosphorylation as a possible contributing mechanism in NO-mediated HIF-1alpha activation [17]. We reported previously that that an N-terminal natriuretic peptide, NP73-102 (also termed KP2), which covers amino acids 73 to 102 of the ANP prohormone, had bronchoprotective and anti-inflammatory activity. Overexpression of NP73-102 increases NO and inactivates ERK1/2 in A549 cells [13]. In order to evaluate whether VD also inactivated ERK1/2, A549 cells were transfected with pVD. Transfection with pVAX1 alone was done as control. Expression of ERK1/2 and phosphorylation of ERK1/2 were analyzed by western blot. There was no significant change in expression of the total amount of ERK1/2 (Fig. 2A); however, significant dephosphorylation was observed in pVD-transfected A549 cells (Fig. 2A) which showed similarity between pVD- and pKP2- treated cells. Therefore, overexpression of VD inactivates ERK1/2.

\section{VD down-regulated NPRA expression}

We have reported that NPRA plays a role in airway inflammation. Knockout of NPRA in mice resulted in less lung inflammation [11]. Inhibition of NPRA by small inferfering RNA against NPRA attenuated lung inflammation in a mouse model of asthma [10]. There is a feedback regulation of the circulating concentration of natriuretic peptides such that ANP decreases kaliuretic peptide and vice versa [18]. Although there is no direct evidence that VD interacts with NPRA, we investigated the effect of VD on NPRA expression. By luciferase assay, it was found that VD significantly decreased NPRA promoter activity up to $99 \%$ ( $\mathrm{p}<0.01$, Fig. 1B). Downregulation of NPRA expression was also observed in HEK-GCA cells transfected with pVD (Fig. 2C) and by RT-PCR in the lungs of mice treated i.n. with pVD NPs (Fig. 2D) compared to pVXA1 and pMut controls. Further molecular mechanism studies are needed to demonstrate whether VD directly binds to the NPRA promoter or affects NPRA transcription though additional cellular factors.

\section{VD reduced airway hyperresponsiveness}

Airway hyperresponsiveness (AHR) is one of the hallmarks of asthma, although it is regulated by a different set of genes from those controlling immunity and inflammation. To determine whether pVD can prevent AHR, pulmonary resistance was measured using the forced oscillation technique in response to increasing concentra- 
A

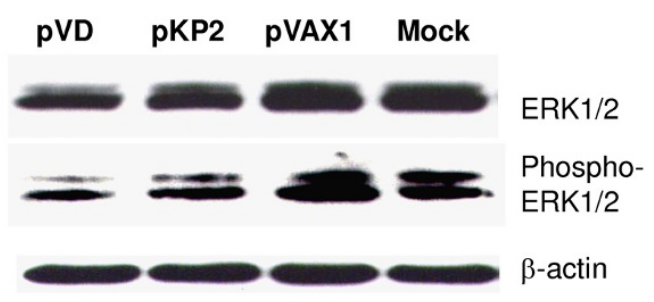

C

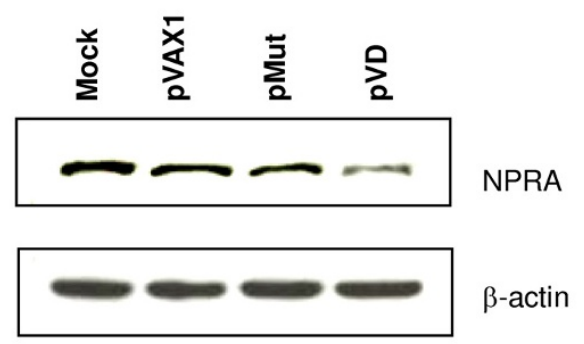

B

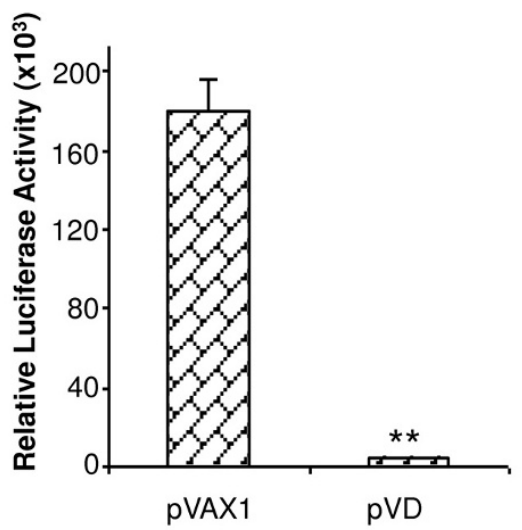

D

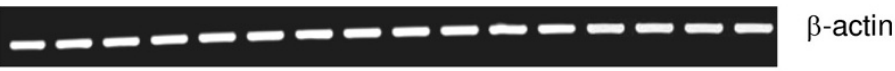

Figure 2

pVD inactivates ERKI/2 and downregulates NPRA expression. (A) A549 cells were transfected with pVD, pKP2 or PVAXI control plasmids. Cells were collected $24 \mathrm{hrs}$ after transfection. Expression of ERKI/2 and phospho-ERKI/2 was detected by western blot. (B) HEK293 cells grown on 96 -well plates were cotransfected with $0.5 \mu \mathrm{g}$ of pNPRA-Luc and I $\mu \mathrm{g}$ PVAXI or PVD. Cells were lysed $48 \mathrm{hrs}$ later and luciferase activity was measured in the lysates $(p<0.0 \mathrm{l})$. (C) Effect of VD on NPRA expression in vitro. HEK-GCA cells were transfected with pVAXI, pVD or pMut. NPRA expression was detected by western blot. Non-transfected cells were used as control. (D). Effect of VD on NPRA expression in vivo. NPRA mRNA expression was detected by RT-PCR in the lungs of mice intranasally treated with chitosan nanoparticles containing $20 \mu \mathrm{g}$ of $\mathrm{pVAXI}$ $(n=4)$, pVD $(n=4)$ or pMut $(n=4)$. Mice from the naïve group $(n=4)$ served as mock controls. All experiments were repeated, and the results of a representative experiment are shown.

tions of aerosolized methacholine ( $\mathrm{MeCh})$. The baseline resistance values for each group were as follows: (1) naïve/ pVAX1, $0.787 \pm 0.242 ;(2)$ OVA/pVD20, $0.882 \pm 0.093$; (3) OVA/pVAX1, $0.676 \pm 0.042$; and (4) OVA, $0.686 \pm$ 0.088 . The baseline values were not statistically different from one another. Airway resistance of mice exposed to OVA alone was not different from that of mice exposed to OVA or the control pVAX1 plasmid. At $25 \mathrm{mg} / \mathrm{ml} \mathrm{MeCh}$, OVA-asthmatic mice treated with pVD had significantly decreased AHR compared to pVAX1-treated control mice exposed to OVA or control mice receiving OVA alone (Fig.
3). In a dose-response analysis, when mice were intranasally treated with NPs containing only $10 \mu \mathrm{g}$ of pVD, less significant protection against AHR was observed (data not shown).

VD treatment attenuated eosinophilia and lung pathology We also evaluated the effect of pVD NPs on lung inflammation in the mouse asthma model. After OVA sensitization and challenge with or without NP treatment, mice were sacrificed and BAL fluids were collected for eosinophil counts. Treatment with pVD NPs significantly 


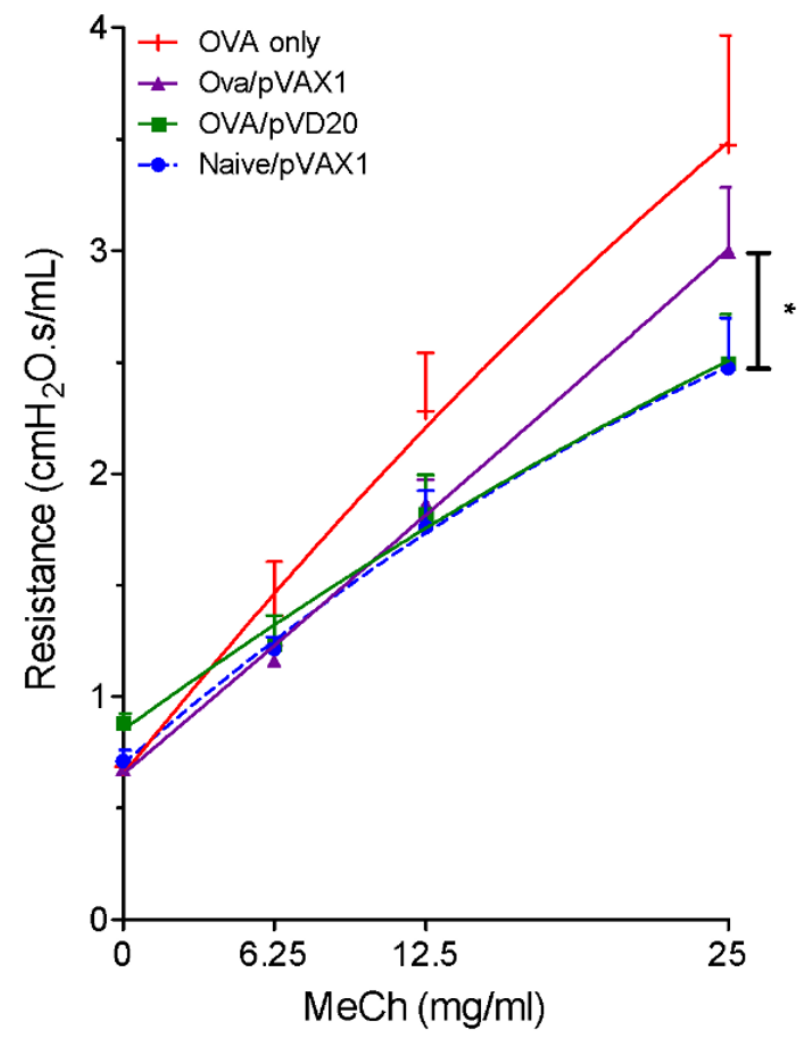

Figure 3

VD prevents airway hyperresponsiveness in the mouse model. Pulmonary resistance was measured using the forced oscillation technique. Mice from each group were treated with methacholine at increasing concentrations. Actual maximum resistance is displayed for each group. Mice given PVD chitosan nanoparticles had significantly lower resistance than those from the OVA control group or the group receiving $P V A X I$ control nanoparticles $(p<0.05)$.

reduced eosinophil recruitment to the lung (Fig. 4A) when compared to treatment with pVAX1 control NPs. To analyze the lung histopathology, the most direct indicator of airway inflammation, lungs were removed for $\mathrm{H} \& \mathrm{E}$ staining. Lung sections from mice treated with VD NPs showed a substantial decrease in inflammation, goblet cell metaplasia, and infiltration of inflammatory cells compared to the pVAX1 control group or the OVA control group with no treatment (Fig. 4B).

\section{VD treatment reduced TH2 inflammatory cytokines IL-4, IL-5 and IL-I 3}

Generation of pathogenic Th2 cells is the main cause of asthma. We measured a panel of proinflammatory cytokines in lung homogenates by using a mouse Th1/
Th2 cytokine CBA kit. Significant reduction of IL-4, IL-5, IL-13 and INF- $\gamma$ was observed in the pVD-treated group when compared to the pVAX1 control group (Fig. 5). However, there was no significant change in IL-2 and TNF$\alpha$ after treatment with pVD NPs. Taken together, the observed changes in proinflammatory cytokines, AHR and lung pathology demonstrate that pVD NPs afford significant protection from airway allergic inflammation.

\section{Discussion}

Here we demonstrate that intranasal treatment with pVD NPs decreases lung inflammation and protects against allergen-induced airway hyperresponsiveness. No VDspecific receptor has been identified, and the mechanism of how VD reduces airway inflammation is unknown. Here we show that VD inactivates ERK1/2 in A549 lung epithelial carcinoma cells, suggesting that VD may achieve its effect by interfering with the ERK1/2 signaling pathway [6,22,19-23].

We also tested whether VD attenuates lung inflammation through its interference with the ANP-NPRA signaling pathway. It has been reported that there is a feedback regulation of the circulating concentration of the N-terminal natriuretic peptide and C-terminal natriuretic peptide such that ANP decreases KP and vice versa [18]. We hypothesized that VD may behave like KP and that overexpression of VD may decrease the level of ANP and its receptor NPRA. We demonstrated that VD reduced NPRA promoter activity in a luciferase assay. Downregulation of NPRA expression was also confirmed both in vitro and in vivo by western blot and RT-PCR. Therefore, the observed attenuation of airway inflammation by VD is consistent with our previous report that NPRA-deficient mice or mice treated with siRNA for NPRA have less eosinophilia and lower levels of Th2-like cytokines compared to wild type mice $[10,11]$.

Since no signal peptide sequence was placed in front of the VD ORF when PVD was constructed in our investigation, expressed VD remains inside the transfected cells (primarily lung epithelial cells). This differs from the normal biology of $\mathrm{VD}$ in which cleavage of the prohormone into N-terminal and C-terminal fragments occurs outside the cell. However, the intracellular expression of VD in lung cells may help us to meet our goal of developing a safe anti-inflammatory drug targeting the respiratory system. Because VD is a cardiovascular hormone, overexpression and circulation of VD may cause side effects. We will test the expression of a secreted form of VD in the future and it will be interesting to compare those results to the current data. Irrespective of the mechanism, the finding that ANP-NPRA is involved in the inflammatory immune response to allergens opens new avenues of research into the pathogenesis of allergic disease and asthma. 
A

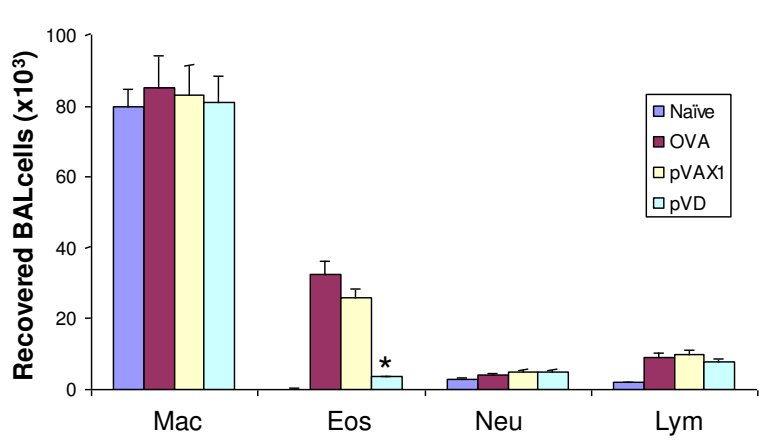

B

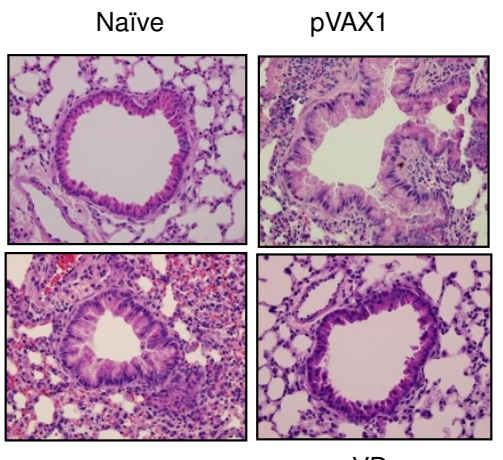

OVA

$\mathrm{pVD}$

Figure 4

VD attenuates lung inflammation in BALB/c mice. (A) Mice were sensitized and challenged with OVA and then given nanoparticles containing PVD or control pVAXI plasmids. Mice were sacrificed $48 \mathrm{hrs}$ after the final treatment, and BAL fluids were collected for differential cell counts. Values are reported as mean \pm SEM. Treatment with $p V D$ significantly reduced eosinophil recruitment to the lungs compared to PVAXI control $(p<0.05)$. Mac, macrophages; Eos, eosinophils; Neu, neutrophils; Lym, lymphocytes. (B) Lung sections from mice treated with VD nanoparticles also showed a substantial decrease in lung inflammation, goblet cell hyperplasia and infiltration of inflammatory cells compared to the non-OVA-challenged group or the group treated with PVAXI. All experiments were repeated and the results of a representative experiment are shown.

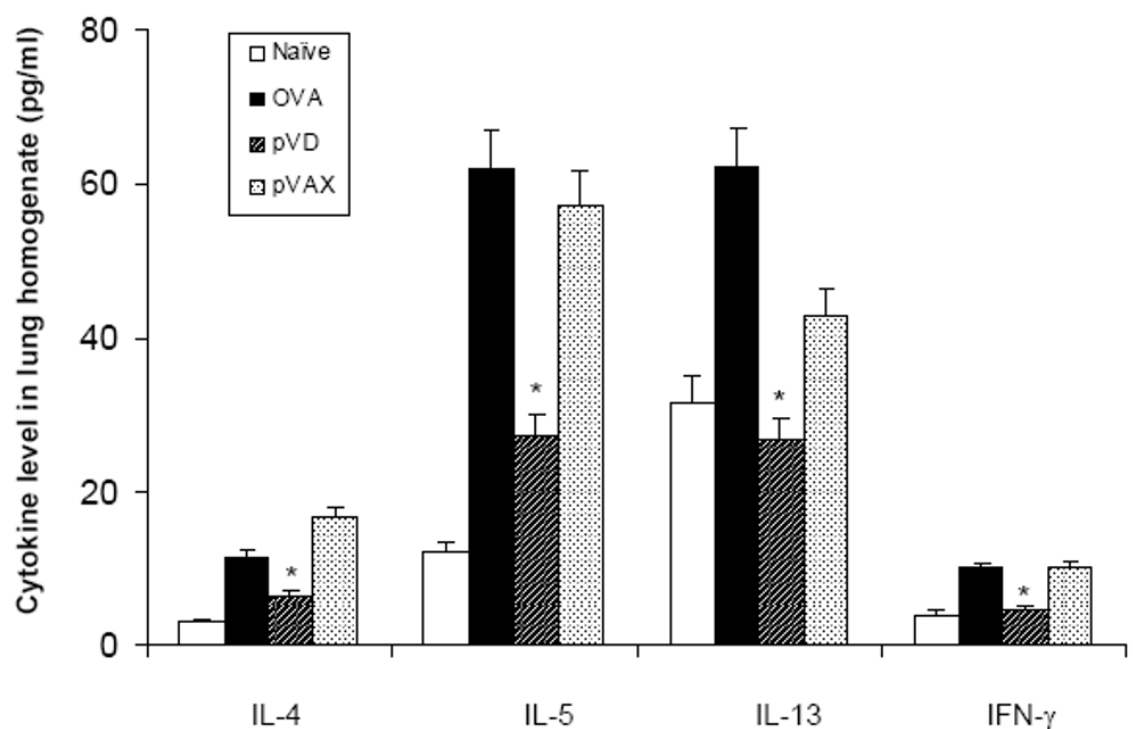

Figure 5

VD reduces proinflammatory cytokines in lung homogenates. Lungs from each group were collected and homogenized. Supernatants of the homogenates were used to measure proinflammatory cytokines with the mouse ThI/Th2 cytokine CBA kit. Significant reduction of IL-4, IL-5, IL-I 3 and IFN- $\gamma$ were observed in the PVD nanoparticle-treated group compared to the OVA and PVAXI nanoparticle-treated group $(p<0.05)$. All experiments were repeated at least once and the results of a representative experiment are shown. 


\section{Conclusion}

The current study demonstrates that vessel dilator, VD, inactivates ERK1/2 and down-regulates NPRA expression. Inhibition of ANP-NPRA and ERK1/2 signaling pathways by VD affords bronchoprotection and anti-inflammatory activity; therefore, chitosan nanoparticles containing VD may be therapeutically effective in preventing allergic airway inflammation.

\section{Competing interests}

The authors declare that they have no competing interests.

\section{Authors' contributions}

SSM, SAC - design of experiments, interpretation of results. $\mathrm{XL}-$ analysis of the results. $\mathrm{XW}, \mathrm{WX}, \mathrm{XK}, \mathrm{DC}, \mathrm{TAA}$, JDG - carrying out cell culture, western blot, luciferase assay. AHR and animal experiments. GH, RL, SM - writing and input in terms of discussion. All authors read and approved the final manuscript.

\section{Acknowledgements}

This study is supported by NIH grant ROI (5HL7I I I IA2), VA Merit Review and Career Scientist Awards and Mabel and Ellsworth Simmons Professorship to SSM and the Joy McCann Culverhouse Endowment to the University of South Florida Division of Allergy and Immunology and by ROI (ESOI5050) to SAC.

\section{References}

I. Arbes SJ Jr, Gergen PJ, Elliott L, Zeldin DC: Prevalences of positive skin test responses to 10 common allergens in the US population: results from the third National Health and Nutrition Examination Survey. J Allergy Clin Immunol 2005, I I 6(2):377-383.

2. Holgate ST, Davies DE, Lackie PM, Wilson SI, Puddicombe SM, Lordan JL: Epithelial-mesenchymal interactions in the pathogenesis of asthma. J Allergy Clin Immunol 2000, $105(2 \mathrm{Pt}$ I): 193-204.

3. Agarwal SK, Marshall GD Jr: Dexamethasone promotes type 2 cytokine production primarily through inhibition of type I cytokines. J Interferon Cytokine Res 200I, 2 I (3): I 47-I55.

4. Ramirez F: Glucocorticoids induce a Th2 response in vitro. Dev Immunol 1998, 6(3-4):233-243.

5. Huang MT, Yang YH, Lin YT, Lu MY, Wang LH, Tsai MJ, Chiang BL: Beta2-agonist exerts differential effects on the development of cord blood T cells but not on peripheral blood T cells. Pediatr Allergy Immunol 200 I, I 2(I): 17-20.

6. Mohapatra SS, Lockey RF, Vesely DL, Gower WR Jr: Natriuretic peptides and genesis of asthma: an emerging paradigm? J Allergy Clin Immunol 2004, I I 4(3):520-526.

7. Vesely DL, San Miguel GI, Hassan I, Gower WR Jr, Schocken DD: Atrial natriuretic hormone, vessel dilator, long-acting natriuretic hormone, and kaliuretic hormone decrease the circulating concentrations of total and tree T4 and free T3 with reciprocal increase in TSH. J Clin Endocrinol Metab 200I, 86(I I):5438-5442.

8. Silberbach $M$, Roberts $C T$ Jr: Natriuretic peptide signalling: molecular and cellular pathways to growth regulation. Cell Signal 200I, 13(4):22I-23I.

9. Lima JJ, Mohapatra S, Feng H, Lockey R, Jena PK, Castro M, Irvin C, Johnson JA, Wang J, Sylvester JE: A polymorphism in the NPPA gene associates with asthma. Clin Exp Allergy 2008, 38(7): $1117-1123$.

10. Wang X, Xu W, Mohapatra S, Kong X, Li X, Lockey RF, Mohapatra SS: Prevention of airway inflammation with topical cream containing imiquimod and small interfering RNA for natriuretic peptide receptor. Genet Vaccines Ther 2008, 6:7.
II. Kong X, Wang X, Xu W, Behera S, Hellermann G, Kumar A, Lockey RF, Mohapatra S, Mohapatra SS: Natriuretic peptide receptor a as a novel anticancer target. Cancer Res. 2008, 68(I):249-256.

12. Kumar M, Behera AK, Lockey RF, Vesely DL, Mohapatra SS: Atrial natriuretic peptide gene transfer by means of intranasal administration attenuates airway reactivity in a mouse model of allergic sensitization. J Allergy Clin Immunol 2002, I I 0(6):879-882.

13. Hellermann G, Kong X, Gunnarsdottir J, San Juan H, Singam R, Behera S, Zhang W, Lockey RF, Mohapatra SS: Mechanism of bronchoprotective effects of a novel natriuretic hormone peptide. J Allergy Clin Immunol 2004, I I 3:79-85.

14. Lee D, Mohapatra SS: Chitosan nanoparticle-mediated gene transfer. Methods Mol Biol 2008, 433: | 27- I 40.

15. Becnel D, You D, Erskin J, Dimina DM, Cormier SA: A role for airway remodeling during respiratory syncytial virus infection. Respir Res. 2005, 6:122.

16. Hamelmann E, Takeda K, Schwarze J, Vella AT, Irvin CG, Gelfand EW: Development of eosinophilic airway inflammation and airway hyperresponsiveness requires interleukin-5 but not immunoglobulin E or B lymphocytes. Am J Respir Cell Mol Biol 1999, 21 (4):480-489.

17. Bove PF, Hristova M, Wesley UV, Olson N, Lounsbury KM, Vliet A van der: Inflammatory levels of nitric oxide inhibit airway epithelial cell migration by inhibition of the kinase ERK $1 / 2$ and activation of hypoxia-inducible factor-I alpha. I Biol Chem 2008, 283(26): 17919-17928.

18. Vesely DL: Atrial natriuretic peptide prohormone gene expression: hormones and diseases that upregulate its expression. IUBMB Life 2002, 53(3): 153-159.

19. He X, Chow D, Martick MM, Garcia KC: Allosteric activation of a spring-loaded natriuretic peptide receptor dimer by hormone. Science 200I, 293(5535): I657-1662.

20. Morita R, Ukyo N, Furuya M, Uchiyama T, Hori T: Atrial natriuretic peptide polarizes human dendritic cells toward a Th2promoting phenotype through its receptor guanylyl cyclasecoupled receptor A. J Immunol 2003, I 70(I 2):5869-5875.

21. Broide DH, Lawrence T, Doherty T, Cho JY, Miller M, McElwain K, McElwain S, Karin M: Allergen-induced peribronchial fibrosis and mucus production mediated by IkappaB kinase betadependent genes in airway epithelium. Proc Natl Acad Sci USA 2005, I 02(49): $17723-17728$.

22. Thomas PG, Carter MR, Da'dara AA, DeSimone TM, Harn DA: A helminth glycan induces APC maturation via alternative NFkappa B activation independent of I kappa B alpha degradation. J Immunol 2005, 175(4):2082-2090.

23. Artis D, Kane CM, Fiore J, Zaph C, Shapira S, Joyce K, Macdonald A, Hunter C, Scott P, Pearce E): Dendritic cell-intrinsic expression of NF-kappa B I is required to promote optimal Th2 cell differentiation. J Immunol 2005, I74(I I):7154-7I59.

Publish with Bio Med Central and every scientist can read your work free of charge

"BioMed Central will be the most significant development for disseminating the results of biomedical research in our lifetime. "

Sir Paul Nurse, Cancer Research UK

Your research papers will be:

- available free of charge to the entire biomedical community

- peer reviewed and published immediately upon acceptance

- cited in PubMed and archived on PubMed Central

- yours - you keep the copyright 